\title{
Ancient human DNA: How sequencing the genome of a boy from Ballito Bay changed human history
}

Marlize Lombard'

Mattias Jakobsson ${ }^{1,2,3}$

Carina Schlebusch ${ }^{1,2}$

\section{AFFILIATIONS:}

'Centre for Anthropological

Research \& Department of Anthropology and Development

Studies, University of

Johannesburg, Johannesburg,

South Africa

${ }^{2}$ Department of Organismal Biology, Evolutionary Biology Centre, Uppsala University, Uppsala, Sweden

${ }^{3}$ SciLife Lab, Uppsala, Sweden

\section{CORRESPONDENCE TO:}

Marlize Lombard

\section{EMAIL:}

mlombard@uj.ac.za

\section{KEYWORDS:}

human genome; huntergatherer; Homo sapiens; population split-time estimations

\section{HOW TO CITE:}

Lombard M, Jakobsson M, Schlebusch C. Ancient human DNA: How sequencing the genome of a boy from Ballito Bay changed human history. S Afr J Sci. 2018:114(1/2), Art. \# a0253, 3 pages. http://dx.doi. org/10.17159/sajs.2018/a0253

(C) 2018. The Author(s). Published under a Creative Commons Attribution Licence.
Being able to extract DNA and then sequence the full genomes of ancient human remains from tropical coasts is often considered precarious because of the warm, humid climate. Yet, we have now demonstrated the successful sequencing of full genomes (i.e. gaining the information of all chromosomes - including autosomes, X-chromosomes, Y-chromosomes and mitochondrial DNA) obtained from Stone Age human remains found along the tropical east coast of southern Africa. ${ }^{1}$ With a minimalist sampling strategy, causing the least amount of morphological damage, we sequenced genome-wide data from three sets of approximately 2000 -year-old human remains found 60 years ago on the Ballito and Doonside beaches of KwaZulu-Natal, South Africa. One set of remains - those of a young boy (Figure 1) - yielded a remarkably complete genome, where every position was covered by sequenced DNA (on average) 13 times. $^{1}$

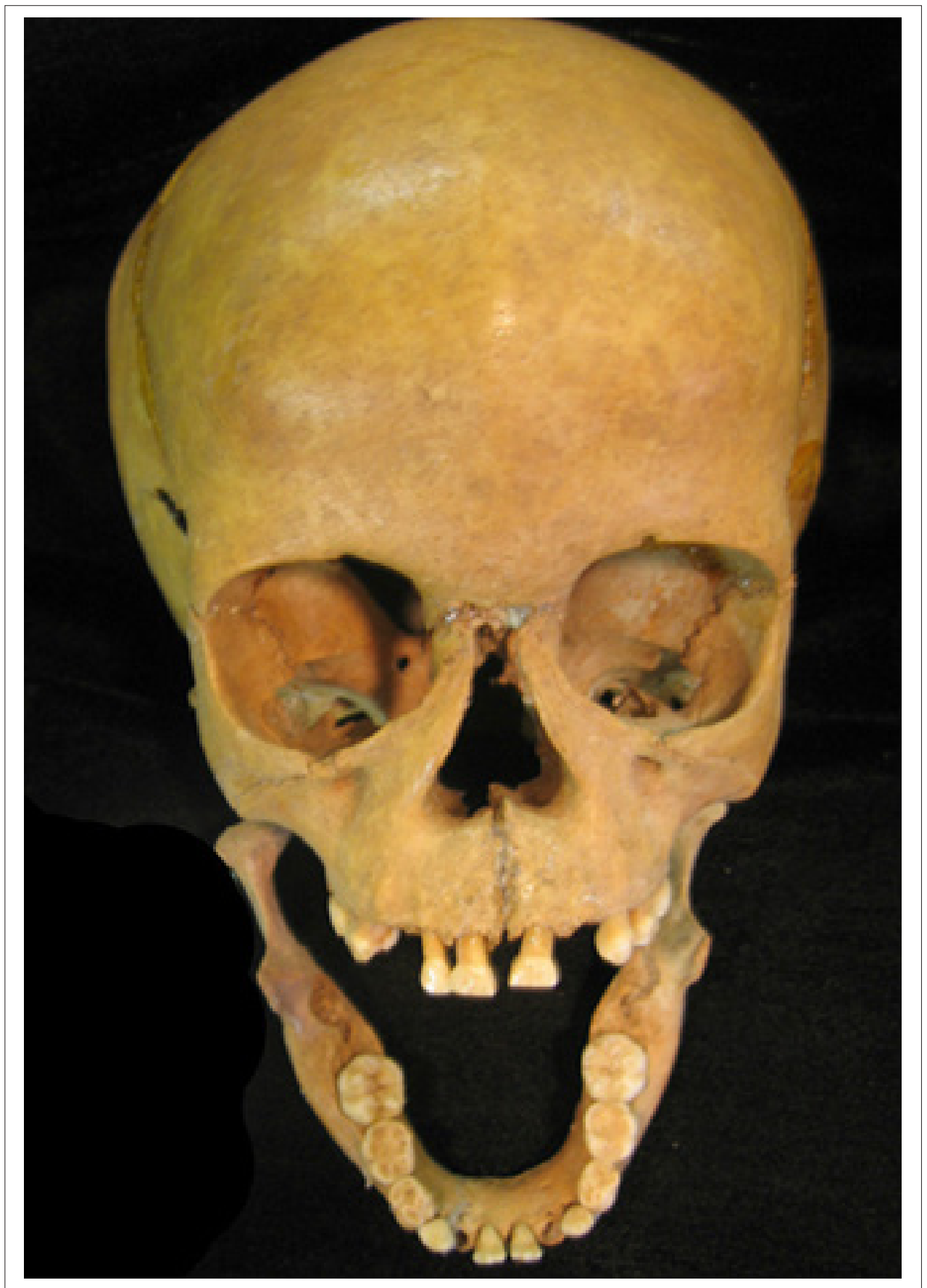

Photo: (CSusan Pfeiffer, University of Toronto, Canada; courtesy of the KwaZulu-Natal Museum, Pietermaritzburg.

Figure 1: The approximately 2000-year-old skull and mandible of the boy from Ballito Bay. 
In contrast to approaches targeting a limited number of markers found polymorphic in some modern populations, ${ }^{2,3}$ whole genomesequence data from ancient remains include the complete and unbiased genetic information carried by an individual. The data potentially also incorporate genetic variants unique to the individual or population. The approach thus allows for direct population genetic analyses of prehistoric individuals, using information on mutations and frequency spectra $^{4}$, such as population split-time estimations ${ }^{1}$, genetic diversity estimates $^{5}$, and changes in effective population size through time $e^{6}$. With increasing numbers of complete, modern-day human genomes becoming available ${ }^{7}$, direct comparison of the entire inherited material will become the norm for population genomic analyses ${ }^{4,8}$, assuring that every possible position in the genomes of ancient individuals can be used for genetic inferences.

Separating the different types of genetic data might be difficult for nonspecialists. For instance, Morris recently noted 'at least two different methodologies that produce different success rates and differing levels of data volume', and highlighted the risks with multiple replicate sampling of ancient human remains. ${ }^{9}$ Yet, every individual carries a specific genome, and the only way to access all its information is to sequence the entire genome, which can be accomplished with a single, small sample. Other types of investigations - such as Y-chromosome, mitochondrial DNA or SNP-capture (single nucleotide polymorphism) approaches harness only a subset of the genetic information in the genome, with various degrees of bias. For example, the SNP-capture approach obtains information on a subset of positions that has been found to be variable in a limited number of individuals living today. As a consequence, variation that is unique to groups that are not currently living, or perhaps were not represented when a SNP-capture array was designed, will be missed. The only way to investigate an unbiased representation of an ancient individual's genome is to sequence it. ${ }^{1,5,6,10,11}$

Three of the seven individuals for whom we generated entire inherited DNA data', lived along the KwaZulu-Natal coast during the final Later Stone $\mathrm{Age}^{12}$. This period was shortly before the influx of pastoralists from East Africa who exchanged their genetic heritage with local huntergatherer groups - forming the historically known Khoekhoe herders of southern Africa - and before farmers of West African descent settled on the landscape from about 1700 years ago, contributing to the local gene pool and giving rise to the local Iron Age. ${ }^{1,13}$

The context of the three Stone Age hunter-gatherers (who displayed no recent admixture with migrating farmers and pastoralists), coupled with the high-quality DNA coverage obtained for the boy from Ballito Bay, provided us with the unique opportunity to recalculate the genetic time depth for our species (Homo sapiens) to between 350000 and 260000 years ago. ${ }^{1}$ Previously, the deepest genetic split was considered to have been between about 160000 and 100000 years ago. ${ }^{14}$ And, based on fossil material from Ethiopia ${ }^{15}$, the oldest modern humans were thought to have lived about 190000 years ago in East Africa. Our work demonstrates that it is the context of human remains that matters when looking at potential deep splits in our lineage, and not their age. However, full-genome data from older remains may yet reveal more surprising outcomes. For example, any additional gene flow into southern African Stone Age populations, predating 2000 years ago, will increase the time depth of the first $H$. sapiens population split.

The new genetic split-time estimate ${ }^{1}$ coincides with the interpretation of fossil material from Morocco in North Africa, dated to about 300000 years $\mathrm{ago}^{16}$, which is seen as anatomically transitional between archaic and modern $\mathrm{H}$. sapiens. It is also consistent with the age of the Florisbad skull that was found in the Free State, South Africa, dated to 260000 years ago. ${ }^{17}$ The Florisbad remains were discovered with Middle Stone Age artefacts, and have been referred to as archaic $\mathrm{H}$. sapiens ${ }^{18}$, representing a combination of archaic and modern characteristics ${ }^{17,19}$, with a cranial volume similar to that of modern humans of about $1300 \mathrm{~mL}$. Other human remains from South Africa dating to between 300000 and 200000 years ago are those from Hoedjiespunt, currently ascribed to $H$. heidelbergensis, because although they are morphologically modern, they seemed larger than modern Africans. ${ }^{20}$
Interestingly, the age range for $H$. naledi fossils from the Rising Star Cave in Gauteng, South Africa, of about 335000 to 236000 years ago, suggests that these small-brained (cranial volume of $465-610 \mathrm{~mL}$ ) hominins co-existed with the large-brained ones. ${ }^{21}$ The southern African geo-cultural landscape during this time is diverse, with stone tool assemblages representing both late Earlier Stone Age and early Middle Stone Age expressions as well as transitional technologies. ${ }^{12}$ The presence of more than one hominin population, each probably occupying its own bio-cultural niche, is therefore not surprising. However, what is unexpected is the marked difference in cranial volume and upper-limb morphology of $H$. naledi compared to $H$. heidelbergensis and $H$. sapiens (both archaic and modern). These differences would indicate that in southern Africa, next to the encephalising lineage/s of our own species, there was ecological space for a small-brained, rock- or tree-climbing hominin. How these physiological traits were expressed in the archaeological record is potentially one of the most interesting puzzles for behavioural and cognitive archaeologists to explore over the next decade or so. Gene-culture co-evolution studies might also be able to contribute to how we understand this complex time in our evolutionary history.

An increased time depth (now based on both fossil ${ }^{16}$ and genetic ${ }^{1}$ data) for the origin of our species in Africa, coupled with the simultaneous existence of a clearly different hominin $(H$. naledi) in southern Africa, and similar looking hominins in different geographical regions of the continent $(H$. sapiens, archaic $H$. sapiens and $H$. heidelbergensis), makes for interesting times in human evolution research. It demands that we take a critical new look at the period between about 350000 and 250000 years ago from a multidisciplinary, continent-wide perspective.

\section{Acknowledgements}

We thank the Human Sciences staff of the KwaZulu-Natal Museum in Pietermaritzburg for access to the human remains, Amafa/Heritage KwaZulu-Natal and SHARA for granting the necessary permits, and Susan Pfeiffer of the University of Toronto for providing us with a photograph of the cranium and mandible of the boy from Ballito Bay. The project was supported by grants from the Knut and Alice Wallenberg Foundation (to M.J.), the Swedish Research Council (no. 642-20138019 to M.J. and no. 621-2014-5211 to C.S.), the Göran Gustafsson Foundation (to M.J.) and an African Origins Platform grant from the South African National Research Foundation (to M.L.).

\section{References}

1. Schlebusch CM, Malmström H, Günther T, Sjödin P, Coutinho A, Edlund H, et al. Southern African ancient genomes estimate modern human divergence to 350,000 to 260,000 years ago. Science. $2017 ; 358: 652-655$. https://doi. org/10.1126/science.aa06266

2. Haak W, Lazaridis I, Patterson N, Rohland N, Mallick S, Llamas B, et al. Massive migration from the steppe was a source for Indo-European languages in Europe. Nature. 2015;5222:207-211. https://doi.org/10.1038/nature14317

3. Skoglund P, Thompson JC, Prendergast ME, Mittnik A, Sirak K, Hajdinjak $\mathrm{M}$, et al. Reconstructing prehistoric African population structure. Cell. 2017;171(1):59-71. https://doi.org/10.1016/j.cell.2017.08.049

4. Nielsen R, Slatkin M. An introduction to population genetics: Theory and applications. Sunderland: Sinauer Associates; 2013.

5. Skoglund P, Malmström H, Omrak A, Raghavan M, Valdiosera C, Günther T, et al. Genomic diversity and admixture differs for Stone-Age Scandinavian foragers and farmers. Science. 2014, 344:747-750. https://doi.org/10.1126/ science. 1253448

6. Prüfer K, Racimo F, Patterson N, Jay F, Sankararaman S, Sawyer S, et al. The complete genome sequence of a Neanderthal from the Altai Mountains. Nature. 2014;505:43-49. https://doi.org/10.1038/nature12886

7. The 1000 Genomes Project Consortium. A global reference for human genetic variation. Nature. 2015;526:68-74. https://doi.org/10.1038/nature15393

8. The International HapMap Consortium. A second generation human haplotype map of over 3.1 million SNPs. Nature. 2007;449:851-861. https:// doi.org/10.1038/nature06258 
9. Morris AG. Ancient DNA comes of age, but still has some teenage problems. S Afr J Sci. 2017;113(9/10), Art. \#a0232, 2 pages. https://doi.org/10.17159/ sajs.2017/a0232

10. Allentoft ME, Sikora M, Sjögren KG, Rasmussen S, Rasmussen M, Stenderup $\mathrm{J}$, et al. Population genomics of bronze age Eurasia. Nature. 2015;522:167172. https://doi.org/10.1038/nature14507

11. Lazaridis I, Patterson N, Mittnik A, Renaud G, Mallick S, Kirsanow K, et al. Ancient human genomes suggest three ancestral populations for presentday Europeans. Nature. 2014;513:409-413. https://doi.org/10.1038/ nature 13673

12. Lombard M, Wadley L, Deacon J, Wurz S, Parsons I, Mohapi M, et al. South African and Lesotho Stone Age sequence updated. S Afr Archaeol Bull. 2012;67:123-144

13. Schlebusch CM, Prins F, Lombard M, Jakobsson M, Soodyall $H$. The disappearing San of southeastern Africa and their genetic affinities. Hum Genet. 2016;135:1365-1373. https://doi.org/10.1007/s00439-016-1729-8

14. Lombard M, Schlebusch C, Soodyall H. Bridging disciplines to better elucidate the evolution of early Homo sapiens in southern Africa. S Afr J Sci. 2013;109(11/12):27-34. https://doi.org/10.1590/sajs.2013/20130065
15. White TD, Asfaw B, DeGusta D, Gilbert H, Richards GD, Suwa G, et al. Pleistocene Homo sapiens from Middle Awash, Ethiopia. Nature. 2003;423(6941):742-747. https://doi.org/10.1038/nature01669

16. Hublin JJ, Ben-Ncer A, Bailey SE, Freidline SE, Neubauer S, Skinner MM, et al. New fossils from Jebel Irhoud, Morocco and the pan-African origin of Homo sapiens. Nature. 2017;546(7657):289-292. https://doi.org/10.1038/ nature22336

17. Grün R, Brink JS, Spooner NA, Taylor L, Stringer CB, Franciscus RG, et al. Direct dating of Florisbad hominid. Nature. 1996;382:500-501. https://doi. org $/ 10.1038 / 382500 \mathrm{aO}$

18. Clarke RJ. Early Acheulean with Homo habilis at Sterkfontein. In: Tobias PV, editor. Hominid evolution: Past, present and future. New York: Alan Liss; 1985. p. 287-298.

19. Curnoe D, BrinkJ. Evidence of pathological conditions in the Florisbad cranium. J Hum Evol. 2010;59:504-513. https://doi.org/10.1016/j.jhevol.2010.06.003

20. Berger LR, Parkington JE. A new Pleistocene hominid-bearing locality at Hoedjiespunt, South Africa. Am J Phys Anthropol. 1995;98:601-609. https:// doi.org/10.1002/ajpa.1330980415

21. Berger LR, Hawks J, Dirks P, Elliott M, Roberts EM. Homo naledi and Pleistocene hominin evolution in subequatorial Africa. eLife. 2017;6, e24234, 19 pages. https://doi.org/10.7554/eLife.24234 